\title{
CONSCIENTIZAÇÃO: Em que interessa este conceito à psicologia ${ }^{1}$
}

\author{
Awareness: In what does this concept interests psychology?
}

\begin{abstract}
Emanuel Meireles Vieira ${ }^{a}$, Verônica Morais Ximenes ${ }^{b}$
a Psicólogo, mestre em Psicologia pela Universidade Federal do Ceará (UFC) e ex-bolsista de mestrado da Fundação Cearense de Apoio ao Desenvolvimento Científico e Tecnológico (FUNCAP), Fortaleza, CE-Brasil, e-mail: emanuel.meireles@yahoo.com.br

${ }^{\text {b }}$ Doutora em Psicologia pela Universidade de Barcelona, professora do Departamento de Psicologia da Universidade Federal do Ceara(UFC) e do mestrado em Psicologia da mesma Universidade e coordenadora do Núcleo de Psicologia Comunitária da UFC (NUCOM), Fortaleza, CE - Brasil, e-mail: vemorais@yahoo.com.br
\end{abstract}

\begin{abstract}
Resumo
Este trabalho tem por objetivo refletir a respeito da apropriação da psicologia do termo conscientização, visto que sua utilização é bastante difundida nas mais diversas áreas do conhecimento, que não só a Psicologia. Para tanto, elabora uma discussão a partir de Paulo Freire, um dos principais propagadores desse termo, utilizando-o em seus trabalhos na área da educação popular, e de Ignácio Martin-Baró, que se apropria deste termo a partir de uma concepção política e o propõe como objetivo da Psicologia na América Latina, mas não explicita o que de exclusivamente psicológico a conscientização possui. Em seguida, discute-se o conceito de atividade comunitária, proposto por Góis na Psicologia Comunitária, para a possível compreensão psicológica do processo de conscientização. Tal discussão traz à tona o conceito de atividade, tal como proposto por Leontiev, no intuito de compreender como a ação do sujeito no mundo incide sobre a formação de seu psiquismo. Aponta, ao final, a Teoria Histórico-Cultural da Mente, desenvolvida por Vigotski, Leontiev e Luria, como a que mais elementos fornece para tal compreensão, uma vez que vincula as formas de significação da realidade ao modo como o indivíduo convive em sociedade, uma vez que tanto os trabalhos de Paulo Freire, quanto de Martin-Baró e Vigotski e seus colaboradores tomam o materialismo histórico-dialético como base filosófica para seu desenvolvimento.
\end{abstract}

Palavras-chave: Conscientização; Psicologia comunitária; Atividade.

\footnotetext{
1 Este trabalho é parte da dissertação de mestrado de Vieira, orientada por Ximenes, e contou com o apoio da Fundação Cearense de Apoio ao Desenvolvimento Científico e Tecnológico (FUNCAP), da qual Vieira era bolsista.
} 


\begin{abstract}
This study has the objective of reflect about the psychological appropriation of the term awareness, once its utilization is world-widely on many kinds of knowledge, not only on Psychology. Therefore, it works out in detail a discussion from Paulo Freire, one of the main multiplyers of this term, using it on his works on the popular education area, and from Ignácio Martin-Baro, who appropriates this term from a political conception and propose it as main objective of the Psychology in Latin America, but he does not explain what there is of exclusively psychologycal on it. After that, it discusses the concept of communitarian activity, proposed by Gois on the Comunitarian Psychology, for the possible psychologycal understanding of the awareness process. This discussion brings to the surface the concept of activity, as proposed by Leontiev, intending to understand how the action of subject on the world arises on the formation of his psychism. It points out, in the end, the historical-cultural mind theory, developed by Vigotski, Leontiev e Luria, as the one that furnishes more elements to that comprehension, once that it entails the ways of reality meaning to the way how the individual cohabits in society, once that Paulo Freire and Martin-Baró's works, as well as Vigotski and his partners's have the historical dialectical materialism as philosophic basis to its development.
\end{abstract}

Keywords: Awarenes; Comunitarian psychology; Activity.

\section{INTRODUÇÃO}

A Psicologia Comunitária, como área da Psicologia Social (Góis, 1994; Lane, 2002), configura-se como possuidora de diversas influências teóricas e práticas. Entre estas influências, podemos encontrar a Educação Libertadora, desenvolvida por Paulo Freire, do qual se utiliza o processo por ele definido como conscientização.

Este termo, advindo da Educação e expandido a diversos campos do conhecimento, é gerador de várias controvérsias. No caso da Psicologia, pode ser lançado o seguinte questionamento: afinal, em que nos interessa, como psicólogos, falar de um termo que ganhou notoriedade no trabalho de um educador como Paulo Freire? Que sentido faz a utilização deste termo num trabalho psicológico? Para além de uma dimensão política da utilização deste conceito, no que pese sua importância, o que de psíquico há presente nele e que merece nossa atenção?

Este trabalho, portanto, constitui-se em torno destas questões. Nesse sentido, para o debate em torno deste termo para a Psicologia, devemos fazer uma breve discussão a respeito dele, tanto a partirde Paulo Freire (1980), como em sua apropriação por Martin-Baró (1998). Em seguida, procuraremos expor de modo mais detalhado o conceito de atividade comunitária e sua possível articulação com a conscientização, uma vez que possuem uma matriz materialista histórica-dialética comum e, portanto, reconhecem a imbricação realidade-formação do psiquismo. Nossa compreensão, portanto, dá-se à luz dos processos psíquicos superiores, propostos pela Teoria Histórico-Cultural da Mente, a partir de Leontiev (1978) e Vigotski (2001).

\section{CONSCIENTIZAÇÃO}

O tema da conscientização é constante na obra de Paulo Freire. Apesar de não ser de sua autoria (FREIRE, 1980), foi em seu trabalho que tal termo ganhou notoriedade. Isso leva, inclusive, a que se pense nele de diversas formas, transitando de uma opção ético-política de transformação social, a uma moral acerca do que se deve conscientizar as pessoas.

No que pesem as controvérsias citadas alhures, Freire (1980, p. 29) define conscientização da seguinte forma: "[...] tomar posse da realidade [...], é o olhar mais crítico possível da realidade, que a 'des-vela' para conhecê-la e para conhecer os mitos que enganam e que ajudam a manter a realidade da estrutura dominante". Como podemos perceber, esta definição extrapola uma dimensão apenas cognoscitiva (o conhecer melhor 
a realidade), pois traz consigo uma concepção política, qual seja, a da transformação desta.

Aliás, o sufixo "ação", que acompanha a palavra em questão, não é obra do acaso, pois indica uma exigência não apenas (apesar de não prescindir dela) de compreensão lógica da realidade, mas também de ações concretas frente a ela. Tal exigência torna-se ainda mais urgente em contextos como o latino-americano, em que uma grande maioria da população vive realidades extremamente desiguais e opressoras, nas quais o direito de pronunciar a sua palavra lhe é constantemente negado, ou permitido na forma de um imenso favor (Freire, 1984; Freire, 1981; Martin-Baró, 1997).

Segundo Góis (2005), Freire via uma profunda imbricação entre contexto históricocultural e compreensão de mundo. É com base nisso que, em "Educação como prática da Liberdade", Freire (1984) expõe as sociedades como podendo ser de três tipos: fechadas, abertas ou de transição. O primeiro tipo carrega consigo a marca da sobreposição de uma elite cada vez mais rica em detrimento de uma grande maioria cada vez mais pobre e subjugada a interesses alheios a suas principais demandas (Góis, 2005).

Já as sociedades em transição se caracterizam por um acirramento pouco profundo entre o que é velho e o que representa o novo, de modo que ambas as idéias são guiadas por um clima de muita emoção em detrimento da resolução das questões urgentes que compõem as contradições sociais. Isso implica em importação de modelos descontextualizados e posturas bastante assistencialistas por parte dos dirigentes (Góis, 2005).

As sociedades abertas, por sua vez, possuem uma relação mais direta entre elite e população em geral, o contexto é levado em conta na efetivação das ações, há uma maior autoconfiança de seu povo, bem como fomento de espaços para uma participação pautada no diálogo. O resultado disso é uma população mais dialógica e que, de fato, volta-se para uma compreensão e transformação mais profunda de suas questões (Góis, 2005).

A cada uma dessas sociedades corresponde, respectivamente, um determinado tipo de consciência. Freire (1984) expõe três tipos ${ }^{2}$ de consciência, correspondentes a cada um desses tipos de sociedade: a semi-intransitiva ${ }^{3}$, a transitivaingênua e a transitiva crítica. Definamos, cada um desses termos, iniciando-se pela semi-intransitiva (correlacionada com o tipo de sociedade descrita anteriormente como fechada), a partir das próprias palavras de Paulo Freire (1984, p. 60):

É evidente que o conceito de "intransitividade" não corresponde a um fechamento do homem dentro dêle mesmo [...]. O homem, qualquer que seja seu estado, é um ser aberto. O que pretendemos significar com a consciência "intransitiva" é a limitação de sua esfera de apreensão.É a sua impermeabilidade a desafios situados fora da órbita vegetativa. Neste sentido, e só neste sentido, é que a intransitividade representa um quase incompromisso do homem com a existência [...].

Como se pode perceber, na consciência semi-intransitiva, o indivíduo apreende a realidade de um modo quase vegetativo, uma vez que esta é compreendida de maneira cristalizada e terminada. Neste estado, o ser não estaria em relação com o mundo, mas apenas em contato com ele. Não estaria, como coloca acima Freire (1984), compromissado com a existência, pois em seu sentido radical, esta palavra (do latim, exsistère deixar-se ver, manifestar-se) denota um lançar-se para fora, ou seja, o ser seria possibilidades e não estagnação numa realidade já acabada.

Os processos do mundo, a partir da apreensão semi-intransitiva, teriam a sua responsabilidade atribuída a uma instância superior, pois "o discernimento se dificulta. Confundem-se as notas dos objetos e dos desafios do contorno e o homem se faz mágico, pela nãocaptação da causalidade autêntica" (Freire, 1984,

\footnotetext{
2 Em verdade, Freire (1984) se refere a níveis de consciência. Góis (2005), contudo, traz a idéia de que seriam tipos. Concordamos com essa idéia, por dar uma noção menos linear e mais transitiva do processo.

3 Freire (1984) se refere a uma consciência intransitiva. Contudo, de acordo com sua própria definição e baseados em Góis (2005), pensamos ser mais apropriada a utilização do termo semi-intransitiva, pois, como Freire expõe acima, nenhuma consciência pode ser completamente intransitiva, uma vez que toda consciência é consciência de alguma coisa. Portanto, para que possa se relacionar com o mundo, precisa estar minimamente aberta.
} 
p. 60). A consciência mágica capta os fatos “[...] emprestando-lhes um poder superior, que a domina de fora e a que tem, por isso mesmo, de submeter-se com docilidade. É próprio desta consciência o fatalismo, que leva ao cruzamento dos braços, à impossibilidade de fazer algo diante do poder dos fatos [...]" (Freire, 1984, p. 105106). A consciência, então, capaz de transitar, movimentar-se, ganha um caráter estático, rígido, tendo em vista que o mundo não se coloca como um problema para ela, mas como um dado.

A transitividade, contudo, segundo Freire (1984, p. 60), não se revela de uma maneira crítica, pois, "[...] num primeiro estado [é] preponderantemente ingênua" (diretamente vinculada ao tipo de sociedade denominada ingênua, de acordo com descrição anterior). De acordo com Freire (1984, p. 60 e 61),

A transitividade ingênua [...] se caracteriza, entre outros aspectos, pela simplicidade na interpretação dos problemas. Pela tendência a julgar que o tempo melhor foi o tempo passado. Pela subestimação do homem comum. Por uma forte inclinação ao gregarismo, característico da massificação. Pela impermeabilidade à investigação, a que corresponde um gosto acentuado pelas explicações fabulosas. Pela fragilidade na argumentação. Por forte teor de emocionalidade. Pela prática não propriamente do diálogo, mas da polêmica [...]. Esta nota mágica, típica da intransitividade, perdura, em parte, na transitividade [...].

A consciência transitiva ingênua, então, forneceria condições para que se pudesse implantar qualquer tipo de tirania contra os seres humanos. Não é à toa que os grandes ditadores sempre têm como apelo a emoção e, ao mesmo tempo, a firme postura de um grande protetor, que não precisa ter algum tipo de preparo específico para administrar um lugar, sob a égide de que "quem ama protege". Como exemplo disso, na História da América Latina, podemos identificar o período da ditadura militar, dos anos 1960 até meados dos anos 1980, em que se utilizavam slogans ufanistas, como "Brasil, ameo, ou deixo-o!".

Já a consciência transitiva-crítica é caracterizada, segundo Freire (1984, p. 61-62), pelos seguintes aspectos:
[...] profundidade na interpretação dos problemas. Pela substituição de explicações mágicas por princípios causais. Por procurar testar os "achados" e se dispor sempre a revisões. Por despir-se ao máximo de preconceitos na análise dos problemas e, na sua apreensão, esforçar-se por evitar deformações. Por negar a transferência da responsabilidade. Pela recusa a posições quietistas. Por segurança na argumentação. Pela prática do diálogo e não da polêmica. Pela receptividade ao novo e pela não-recusa ao velho, só porque velho, mas pela aceitação de ambos enquanto válidos. Por se inclinar sempre a argüições.

Este tipo de consciência, portanto, analisa com maior profundidade os fatos, mostrase mais aberta, democrática e, ao mesmo tempo, mais inquieta, pois as indagações são seu ponto de partida. A conscientização, portanto, é um processo que incita a participação popular de modo efetivo, superando a mera cidadania dos direitos, indo em direção a uma cidadania ativa (Benevides, 1991), na qual o povo passa a se pronunciar acerca de que direitos quer ter, e não apenas usufruir direitos elaborados de modo alheio a suas reais necessidades. Mas, afinal, que relações podemos estabelecer entre este conceito e o psiquismo humano? Em que nos interessa esta categoria, desenvolvida por um educador e que, apesar de apontar, não nos define qual sua concepção explícita de psiquismo?

O surgimento da Psicologia Comunitária no Brasil, inclusive, está ligado à pergunta acima, pois, segundo Lane (2002), de um começo assistencialista, preocupado com a mera presença do psicólogo no auxílio a populações "carentes", a Psicologia Social passou a se perguntar acerca de sua utilidade no que diz respeito à emancipação das populações oprimidas. De acordo Lane (2002) e Góis (2003), um dos referenciais teóricometodológicos muito utilizados naquele período de surgimento da Psicologia Comunitária no Brasil era o trabalho em Educação Popular desenvolvido por Paulo Freire.

No que pese a importância dos trabalhos inicias com Psicologia Comunitária a partir de Freire, não havia uma compreensão clara da relação entre as condições materiais da vida cotidiana e o desenvolvimento do psiquismo. Em relação à utilização do termo "conscientização", podemos 
afirmar que se tratava de uma concepção muito mais política do que necessariamente psicológica.

\section{POR UMA CONCEPÇÃO POLÍTICA NA PSICỎLOGIA}

Um dos grandes defensores da utilização do termo "conscientização" para a Psicologia é Martin-Baró, psicólogo espanhol, mas de intensa atividade em El Salvador. Ignácio Martin-Baró viu no trabalho de Paulo Freire elementos de essencial contribuição para a construção de uma Psicologia da Libertação (Martin-Baró, 1998). Esse autor define o papel do psicólogo como o de contribuir para a transformação da realidade de opressão em que vive a maioria das pessoas da América Latina.

Segundo Martin-Baró (1997, p. 15), “à luz desta visão [da transformação da realidade] da psicologia, pode-se afirmar que a conscientização constitui-se no horizonte primordial do quefazer psicológico". O autor define conscientização a partir de Paulo Freire e afirma se tratar do "[...] processo de transformação pessoal e social que experimentam os oprimidos latino-americanos quando se alfabetizam em dialética com o seu mundo" (Martin-Baró, 1997, p. 15-16).

O trabalho do psicólogo, na perspectiva acima, diria respeito a facilitar que as pessoas pronunciem suas palavras e, para tanto, é preciso "que as pessoas assumam seu destino, que tomem as rédeas e sua vida, o que lhes exige superar a falsa consciência e atingir um saber crítico sobre si mesmas, sobre seu mundo e sobre sua inserção nesse mundo" (Martin-Baró, 1997, p. 16). Desta forma, o horizonte ético sobre o qual se funda a Psicologia na América Latina não poderia ser outro que não o da libertação.

Vale lembrar que o período em que Martin-Baró produziu seus trabalhos foi marcado por uma efervescência das discussões em torno do papel das ciências humanas em torno das desigualdades que constituem a América Latina. Portanto, assim como no Brasil podemos ver em Silvia Lane $(1995 ;$ 2002) alguém que chamou atenção da necessária mudança de perspectiva da Psicologia no Brasil, podemos afirmar que Martin-Baró (1997; 1998), em sua produção, afirma peremptoriamente a impossibilidade de a produção dessa ciência em toda a região latino- americana passar incólume a respeito da imbricação realidade-constituição do psiquismo (Blanco, 2001).

Lembramos esse fato para ressaltar a importância de seu trabalho, bem como a falta de uma explicitação psíquica do funcionamento da conscientização. Era um período em que se tornava necessário expor a descontextualização da Psicologia, no que pese um não-saber ao certo o que colocar no lugar de uma tradição psicológica considerada descontextualizada.

Blanco (2001), analisando a epistemologia da Psicologia Social na América Latina a partir da obra de Martin-Baró, situa a produção deste autor num realismo crítico, marcado por uma primazia da realidade, uma necessidade de se historicizar o psiquismo e a inevitabilidade de comprometer-se. Isso implica numa visão de sujeito e de sociedade, na qual o sujeito é histórico, com amplas possibilidades de utilizar o aparato histórico-cultural de que dispõe, bem como de criar outros a partir destes e modificar sua realidade. Esta, por sua vez, não é estática, e deve contar com a participação daqueles que a constituem. Nesse sentido, a sociedade vislumbrada pelo realismo crítico de Martin-Baró é sobretudo justa, com oportunidades para que este sujeito que permeia sua práxis possa se desenvolver, o que significa mudança nas condições materiais deste desenvolvimento.

Martin-Baró (1998) aposta na conscientização como processo fundamental no trabalho do Psicólogo que intenta trabalhar a partir de seu realismo crítico, tomando de Paulo Freire esta noção. A conscientização, segundo Martin-Baró (1998, p. 147), "não consiste numa simples mudança de opinião sobre a realidade, numa mudança da subjetividade individual que deixe intacta a situação objetiva: a conscientização supõe uma mudança das pessoas no processo de mudar suas relações com o meio-ambiente e, sobretudo com os demais". É nesse sentido que Blanco (2001) afirma que a proposta de MartinBaró é sócio-histórica. O desenvolvimento pessoal não prescinde, portanto, de mudanças estruturais nas estruturas sociais opressoras em que por vezes estão inseridas as maiorias da América Latina.

Apesar de chamar atenção à contextualização do fazer psicológico na América Latina, Martin-Baró (1997; 1998) não explicita o 
significado disso em termos de processos psíquicos. Apesar das semelhanças e até mesmo de uma certa teoria de psiquismo implícita ao realismo crítico de Martin-Baró, cabe aos estudiosos de sua produção realizar essa associação. Blanco (2001) e Góis (2005), por exemplo, apontam a teoria de Vigotski e seus colaboradores como uma grande interlocução para a compreensão deste processo. E é a partir de uma possibilidade desta aposta que seguiremos este trabalho: uma compreensão do processo de conscientização a partir da teoria histórico-cultural da mente, tomando como conceito primordial o conceito de atividade comunitária desenvolvido por Góis (2005).

\section{ATIVIDADE COMUNITÁRIA}

O conceito de atividade comunitária está ancorado na Teoria da Atividade, desenvolvida por Alexis Leontiev. Esta teoria estabelece um elo indissolúvel entre mudanças materiais e subjetivas, uma vez que sua tese central é a de que o trabalho acarretou na hominização do cérebro. Trabalho aqui é compreendido de acordo com a definição de Leontiev (1978, p. 1975), segundo a qual:

O trabalho humano [...] é uma actividade (sic) originariamente social, assente na cooperação entre indivíduos que supõe uma divisão técnica, embrionária que seja, das funções do trabalho; assim, o trabalho é uma acção (sic) sobre a natureza, ligando entre si os participantes, mediatizando a sua comunicação.

Dessa forma, podemos perceber no trabalho as dimensões cooperativa e comunicativa que o envolvem, uma vez que a decomposição da atividade em determinadas ações pressupõe que elas se liguem pela relação entre o indivíduo e os membros da coletividade. Assim, a atividade é permeada por significado social e não apenas por uma mera satisfação instintual.

É nesse sentido que Leontiev (1978, p. 70) afirma:

O aparecimento e o desenvolvimento do trabalho, condição primeira e fundamental da existência do homem, acarretaram a transformação e a hominização do cérebro, dos órgãos de actividade (sic) externa e dos órgãos dos sentidos [...]. O órgão principal da actividade (sic) do trabalho do homem, a sua mão, só pode atingir a sua perfeição graças ao próprio trabalho.

Ainda segundo Leontiev (1978, p. 86):

No trabalho os homens entram forçosamente em relação, em comunicação uns com os outros. Originariamente, as suas acções (sic), o trabalho propriamente, e a sua comunicação formam um processo único. Agindo sobre a natureza, os movimentos de trabalho dos homens agem igualmente sobre os outros participantes na produção. Isto significa que as acções (sic) do homem têm nestas condições uma dupla função: uma função imediatamente produtiva e uma função de acção (sic) sobre os outros homens, uma função de comunicação.

Assim, podemos perceber que a atividade traz consigo a marca da cooperação, de modo que é impossível pensá-la a partir de um único homem isolado. A atividade pode, por exemplo, ser decomposta em diversas ações necessárias para que ela ocorra, de modo que se abre a possibilidade (eminentemente humana) de se refletir psiquicamente a relação entre o motivo da ação e o objeto, uma vez que a ação não se encerra nele.

A atividade humana se orienta, portanto, a partir de um referencial social, de uma série de significados que extrapolam os limites daquilo que, naturalmente, seria-lhes designado. Leontiev (1978) nos dá o exemplo de uma caça. Dividida esta atividade em algumas ações, teríamos, por exemplo, a de alguém que executaria a ação de assustar a presa e direcioná-la a um local que forneça melhores condições para que esta seja capturada por outro grupamento que depende diretamente da boa execução da tarefa daquele que espanta a caça. Dessa forma, poderíamos compreender que a atividade em questão é a caça, enquanto que o ato de espantar a caça e a sua captura propriamente dita são algumas das ações que compõem esta atividade.

De um modo isolado, poderíamos pensar a ação de espantar o alvo da caça como algo contraditório ao objetivo do trabalho, uma vez que o que se quer é capturar a presa. Contudo, a ação do batedor se liga a de outros que com ele capturarão a caça. Conforme Leontiev (1978, p. 80): 
Para que um homem se encarregue da sua função de batedor, é necessário que as suas ações estejam numa correlação para que ela "exista para ele"; por outros termos, é preciso que o sentido das suas ações se descubra, que ele tenha consciência dele. A consciência da significação e uma acção (sic) realiza-se sob a forma de reflexo do seu objecto (sic) enquanto fim consciente.

A possibilidade do discernimento da ação envolvida numa atividade coletiva se dá por meio da capacidade humana de não se fundir com o objeto, mas sim como uma relação em que o objeto é destacado num objetivo maior. Dessa forma, o conceito de caça, no exemplo anterior, passa a se sobrepor ao que instintivamente apareceria apenas como uma presa, pois a consciência a distinguiu e significou dessa maneira.

De fato, o grande salto que a humanidade dá em relação aos outros animais e que possibilita essa ação planejada do homem sobre a natureza é a criação de instrumentos. Os trabalhos realizados pelos homens possuem essa peculiaridade: sua realização mediante determinados meios. Nossa compreensão de instrumento é ancorada na definição de Leontiev (1978, p. 82), segundo a qual "o instrumento é [...] um objeto com o qual se realiza uma ação de trabalho, operações de trabalho".

A utilização de instrumento está estreitamente vinculada à consciência do fim da ação. Dessa forma, ele deixa de ser um mero objeto e passa a carregar consigo conceitos que ultrapassam uma condição natural. E nesse sentido que Leontiev (1978, p. 82) afirma que "[...] é o instrumento que é de certa maneira portador da primeira verdadeira abstração consciente e racional, da primeira generalização consciente e racional".

Há, portanto, uma significação que atravessa o instrumento. De um graveto, à utilização de um microcomputador, vivemos o tempo todo utilizando instrumentos para lidar com a realidade, transformando-a e desnaturalizando-a. Por se tratar de uma relação dialética, o homem também se transforma e se desnaturaliza. Além disso, a utilização de um instrumento traz consigo uma experiência social, pois há um significado compartilhado em torno dele.

O significado atribuído à ação e ao instrumento por meio da consciência só se torna possível mediante o mais elaborado instrumento desenvolvido pela humanidade: a linguagem. Segundo Leontiev (1978, p. 87), "significando no processo de trabalho um objeto, a palavra distingue-o e generaliza-o para a consciência individual, precisamente na sua relação objectiva (sic) e social, isto é, como objecto (sic) social". Segundo Góis (2005), devido a essa vinculação do instrumento a uma significação, a atividade cumpre uma função mediatizadora, o que proporciona o desenvolvimento dos processos psicológicos superiores. Ainda segundo o autor, além da função mediatizadora, a atividade carrega consigo uma função orientadora, pois proporciona ao indivíduo possibilidades de melhor compreensão de sua situação.

Ancorado nas investigações de Leontiev (1978), Góis (1994) desenvolve o conceito de atividade comunitária. Aliás, é a partir da análise e da vivência da atividade comunitária que se dá a intervenção em Psicologia Comunitária. Segundo Góis (1994, p. 86), "a análise e a vivência da atividade comunitária, isto é, do processo interativo e coletivo pelo qual o indivíduo vivencia e interioriza a realidade do lugar/comunidade, a transforma e aprofunda sua consciência de si e do mundo, constitui o método principal da psicologia comunitária”.

O autor define atividade comunitária como:

A atividade prática e coletiva realizada por meio da cooperação e do diálogo em uma comunidade, sendo orientada por ela mesma e pelo significado (sentido coletivo) e sentido (significado pessoal) que a própria atividade e a vida comunitária têm para os moradores da comunidade. Ela é uma rede de interações sociais, instrumental e comunicativa, direcionada para a autonomia do morador e da própria comunidade, na perspectiva do fortalecimento de uma identidade social [...] de comunitário, do desenvolvimento da consciência social e pessoal, e da construção da responsabilidade comunitária. (Góis, 2005, p. 89).

Ter a análise e vivência da atividade comunitária como método:

significa dar prioridade à transformação objetiva da realidade e ao desenvolvimento da consciência pessoal e social em um só processo de desenvolvimento, no qual são 
essenciais a ação-discurso, o diálogoproblematizador, a conscientização, o conhecimento crítico e a transformação solidária da realidade. (Góis, 2005, p. 87).

Assim como na teoria da atividade de Leontiev (1978), entre as características do conceito de atividade comunitária que nos fornece Góis encontra-se a de conter interações instrumentais e comunicativas. As interações instrumentais “[...] são [...] voltadas para a elaboração e uso de instrumentos com finalidades comunitárias, seja tecnologias simples [...] ou tecnologias avançadas" (Góis, 2005, p. 86). Já a dimensão comunicativa "[...] compreende o diálogo, a expressão de sentimentos e a cooperação entre os moradores, no intuito de alcançar os objetivos da atividade comunitária e favorecer o desenvolvimento das relações sociais na comunidade" (Góis, 2005, p. 86).

Como no exemplo do batedor, dado por Leontiev, podemos pensar numa reunião e quarteirão, metodologia exposta por Góis (2003), na qual moradores de determinada área da comunidade dialogavam, num espírito festivo e problematizador, acerca das questões que dizem respeito a seu cotidiano e buscam de modo cooperativo uma resolução para elas. Evidentemente, as questões, de modo geral, não possuem solução imediata. Contudo, as pessoas que participam destes encontros podem, assim como o batedor da caça, se perceber como parte de um processo que depende de sua organização e diálogo.

Como podemos perceber, a comunidade passa a ser o locus privilegiado de interação e de surgimento do psiquismo. Dessa forma, podemos afirmar que o cotidiano fornece elementos preciosos para a compreensão e a atuação por parte daqueles que intentam trabalhar com desenvolvimento humano de maneira geral. É nesse sentido que, a partir de Góis (2005, p. 61), definimos comunidade como:

[...] um lugar de moradia, um 'hogar' social, de permanência estável e duradoura, de relação direta (face-a-face) entre seus moradores, de crescimento e de proteção da individualidade frente à natureza e à sociedade. Apresenta, como o município e a sociedade maior, que exercem influência sobre ela, um processo social próprio cheio de contradições, conflitos e interesses comuns, que servem de base à construção e orientação das ações de seus moradores com relação a próprio lugar, ao município onde se encontra e ao conjunto da sociedade.

Esta perspectiva força a uma redefinição da atuação, por exemplo, dos psicólogos, que, de modo geral, apesar de perceberem a insuficiência dos métodos tradicionais (principalmente clínicos), não sabem como agir na direção de uma psicologia do cotidiano (Barros, 2007). Esta perspectiva corrobora com a de Vigotski (2001, p. 149), segundo a qual " $[. .$.$] devemos esperar [...] que, em$ linhas gerais, o próprio tipo de desenvolvimento histórico do comportamento venha a estar na dependência direta das leis gerais do desenvolvimento histórico da sociedade humana".

É por se basear em tal perspectiva que Góis (2003) propõe como duas das condições para a criação de um clima psicossocial de crescimento pessoal e social - com congruência, aceitação, empatia e diálogo - a organização comunitária e a luta reivindicatória e política, que criam condições para que o indivíduo possa se colocar de uma maneira mais crítica diante de sua realidade, pois tal forma de organização da atividade está imbricada com uma diferente organização do psiquismo. Vale ressaltar que, por se tratar de um processo não apenas dialético, mas também dialógico, isso implica em mudanças não apenas nos moradores, mas também no psicólogo, que sai de sua tradicional distância profissional e passa a experimentar outras formas de interação. E nesse sentido que Góis (1994, p. 89) afirma que:

A relação morador-psicólogo, no interior da atividade comunitária, constitui um processo de facilitação da vida comunitária, no qual o Psicólogo Comunitário e os moradores atuam em conjunto, seguindo linhas de encontro, reflexão e ação no intuito de melhorar a qualidade da vida psíquica dos moradores e do próprio Psicólogo Comunitário, no que diz respeito à construção de sujeitos sociais e comunitários.

As implicações de formas de interações diferenciadas de interação, tanto em sua dimensão comunicativa (dialógico), quanto instrumental (transformação solidária da realidade) foram objeto de estudos e atuação tanto de Paulo Freire 
quanto de Martin-Baró, conforme exposto alhures. Mas afinal, como podemos compreender psiquicamente o processo de conscientização? Qual a relevância deste conceito para um trabalho especificamente de Psicologia?

\section{ATIVIDADE COMUNITÁRIA E CONSCIENTIZAÇÃO: ESBOÇO DE UMA POSSÍVEL RELAÇÃO}

Estabelecer paralelos entre esses conceitos exige, de imediato, um cuidado importante: o de saber que se tratam de conceitos produzidos em áreas díspares do conhecimento e que, portanto, contêm as especificidades de cada uma dessas áreas. Contudo, essa comparação pode ser iniciada a partir do reconhecimento de uma matriz comum ao pensamento de Vigotski e seus colaboradores (em especial Leontiev) e aos de Paulo Freire e Martin-Baró: o materialismo histórico-dialético. Em ambas as perspectivas, é possível encontrar referências a Marx ou a autores de notória inspiração marxista.

Isso implica numa necessária imbricação, em ambas as teorias, entre realidade material e subjetividade, pois adotar o materialismo históricodialético como fundamento epistemológico para a construção de um pensamento traz consigo implicações éticas e epistemológicas. No campo ético, significa deixar de lado qualquer concepção de neutralidade em que possa ser pensada a construção do conhecimento, pois se reconhece nesta uma exigência de vinculação direta com as questões do tempo e do lugar em que é desenvolvida. Já no âmbito epistemológico, significa que "o pesquisador [...] deve ter presente em seu estudo uma concepção dialética da realidade natural e social e do pensamento, a materialidade dos fenômenos e que estes são possíveis de conhecer" (Triviños, 1987, p. 73).

A respeito desta imbricação entre realidade social e construção do pensamento, Góis (2005, p. 111) afirma que, "na Pedagogia da Libertação, assim como na Teoria HistóricoCultural da Mente, [...] o ponto de partida para o desenvolvimento do individuo é sua ação transformadora do mundo [...]. Para ambos, a consciência se origina no ato de transformar a realidade e não na adaptação".

Uma das condições necessárias para que desenvolva um processo de conscientização é o estabelecimento do diálogo, compreendido de acordo com a definição de Freire (1981, p. 93):

O diálogo é este encontro de homens, mediatizado pelo mundo, para pronunciá-lo [...]. Esta é a razão por que não é possível o diálogo entre os que querem a pronúncia do mundo e os que não a querem; entre os que negam aos demais o direito de dizer a palavra e os que se acham negados deste direito. É preciso primeiro que, os que assim se encontram negados no direito primordial de dizer a palavra, reconquistem este direito, proibindo que este assalto desumano continue [...]. O diálogo é uma exigência existencial.

Isso significa que ao outro é reconhecida a importância do direito de dizer a sua palavra, de modo que há uma interação que permite a participação de todos, em que cada um tem a possibilidade de escrever, de modo coletivo, a história de todos.

Além de uma óbvia implicação ética - o reconhecimento do outro - o diálogo parece mediar um processo psíquico no qual a percepção da realidade, bem como o modo de agir diante dela sofrem profundos impactos e merecem, sem dúvida, uma investigação mais acurada. Góis (2005, p. 110) reconhece esse processo psíquico como "[...] um mecanismo de interiorização da realidade físico-social, em sua diversidade e mudança, e ao mesmo tempo de expressão do indivíduo no mundo". O autor, portanto, reconhece esse nexo psíquico presente no processo de conscientização ancorado na concepção de psiquismo presente na Teoria Histórico-Cultural da Mente.

Para uma melhor compreensão deste processo, retomemos a concepção de psiquismo presente na obra de Leontiev. Para ele, "o reflexo psíquico resulta de uma relação, de uma interação real entre um sujeito material vivo, altamente organizado, e a realidade que o cerca" (Leontiev, 1978, p. 93).

Ora, como podemos perceber, adotar o conceito de consciência exposto acima significa reconhecer que o desenvolvimento dela (consciência) necessariamente envolve a superação de uma apreensão natural da realidade. É dada ao homem possibilidade de não apenas se adaptar à realidade, pois ele pode se distanciar dela e deve, sobretudo, transformá-la. E o que 
significa a conscientização, senão a superação de uma apreensão quase espontânea da realidade?

Desta forma, podemos compreender a conscientização e a atividade comunitária como fazendo parte de um único processo. Afinal, conforme expusemos anteriormente a partir de Leontiev (1978), a interação com a realidade, por meio de suas dimensões instrumental e comunicativa, produz mudanças na forma de o indivíduo se relacionar consigo, com o outro e com o mundo, pois a atividade comunitária possui uma função orientadora. Esse movimento (dialético) de mútua transformação ocorre num mundo de significados (sentidos compartilhados de maneira coletiva), daí por que ser uma atividade e não uma mera ação sobre a realidade.

A conscientização, por sua vez, possui, assim como a atividade comunitária, dimensões comunicativas e instrumentais. $\mathrm{O}$ aspecto instrumental da conscientização se dá pelo fato de esta não prescindir da problematização em torno de palavras, e palavra é vista aqui como "significação produzida pela 'práxis', palavra cuja discursividade flui da historicidade - palavra viva e dinâmica, não categoria inerte exâmine. Palavra que diz e transforma o mundo" (Fiori, 1979, p. 15). Já o aspecto instrumental da conscientização se manifesta na elaboração de instrumentos que auxiliem na transformação da realidade, comissões de mobilização e ação e confecção de instrumentos para uma manifestação pública, por exemplo. $\mathrm{O}$ diálogo problematizador, portanto, parece criar uma ambiência propícia para um desenvolvimento do ser humano na direção de seu reconhecimento como ser histórico e, conseqüentemente, inacabado.

\section{CONSIDERAÇÕES FINAIS}

A compreensão da conscientização como parte do desenvolvimento dos processos psíquicos superiores (nas palavras de Vigotski), é fundamental para que se possa compreender a especificidade desta perspectiva no trabalho do psicólogo. Não é raro ouvirmos que o diferencial do Psicólogo numa equipe multiprofissional é a escuta, o que é muito pouco. Nossa formação clínica sem dúvida favorece que tanto nós, como outros profissionais, esperemos is to, e a imagem que daí advém é a de um grande ouvido.

Por outro lado, o compromisso social apenas não basta para o desenvolvimento de um trabalho com Psicologia Comunitária. Pode, inclusive, ser um ponto de partida, mas deve envolver a compreensão deste trabalho à luz de uma teoria psicológica, até mesmo para que se possa diferenciar o militante do profissional de Psicologia. Para que não seja apenas um psicólogo engajado, mas sim uma Psicologia que apresente como ferramenta para esse compromisso social. Vemos na Teoria Histórico-Cultural da Mente (Vigotski, Luria e Leontiev) uma teoria de enorme potencial para que possamos compreender os meandros do processo nomeado por Martin-Baró e Paulo Freire de conscientização, em termos de desenvolvimento dos processos psíquicos superiores.

Evidentemente, tal afirmação merece uma investigação empírica e mais detalhada acerca do processo de conscientização, bem como das mediações que lhe sustentam. Por ora, as evidências teóricas tendem a nos fazer concordar com Góis (2005, p. 118) quando afirma que "analisando as concepções de consciência em Vigotski e Paulo Freire, vemos que entre elas não há uma oposição, mas uma ampliação e adequação às questões do desenvolvimento sócio-econômico e da educação, especialmente nos países pobres".

\section{AGRADECIMENTOS}

Agradecemos à Fundação Cearense de Apoio ao Desenvolvimento Científico e Tecnológico (FUNCAP) pelo apoio para a realização desta pesquisa.

\section{REFERÊNCIAS}

Benevides, M. V. M. (1991). A Cidadania ativa: Referendo, plebiscito e iniciativa popular. São Paulo: Ática. 
Barros, J. P. P. (2007). Considerações sobre a práxis do(a) psicólogo(a) nas raízes de cidadania e no centro de referência da assistência social (CRAS) de Fortaleza. Monografia de graduação Universidade Federal do Ceará, Fortaleza.

Blanco, A. (2001). Hacia uma Epistemologia Psicossocial Latinoamericana: El realismo crítico de Ignácio Martin-Baró. In: A. M. F., Caniato, \& E. A Tomanik, (Org.). Compromisso social da psicologia. Porto Alegre: ABRAPSOSUL.

Fiori, E.M. (1979). Aprender a dizer a sua palavra. In: P, Freire. Pedagogia do Oprimido. Rio de Janeiro: Paz e Terra.

Freire, P. (1980). Conscientização: Teoria e prática da libertação: uma introdução ao pensamento de Paulo Freire. São Paulo: Cortez e Moraes.

Freire, P. (1981). Pedagogia do oprimido. Rio de Janeiro: Paz e Terra.

Freire, P. (1984). Educação como prática da liberdade. Rio de Janeiro: Paz e Terra.

Góis, C. W. L. (1994). Noções de psicologia comunitária. Fortaleza: Viver.

Góis, C. W. L. (2003). Psicologia comunitária no Ceará: Uma caminhada. Fortaleza: Publicações Instituto Paulo Freire de Estudos Psicossociais.

Góis, C. W. L. (2005). Psicologia Comunitária: Atividade e vivência. Fortaleza: Publicações Instituto Paulo Freire de Estudos Psicossociais.

Lane, S. T. M. (2002). Histórico e fundamentos da Psicologia Comunitária no Brasil. In R. H. F., Campos. Psicologia Comunitária: Da solidariedade à autonomia. (pp. 17-34). Petrópolis: Vozes, p. 17-34.

Lane, S. T. M. (1995). A Psicologia Social e uma nova concepção de homem para a Psicologia. In: Lane, S. T. M., \& W., Codó. Psicologia social: O homem em movimento. (pp.1019). São Paulo: Brasiliensep.

Leontiev, A. N. (1978). O Desenvolvimento do Psiquismo. Lisboa: Horizonte Universitário.

Martin-Baró, I. (1998). Psicología de 1a liberación. Madrid: Editorial Trotta.

Martin-Baro, I. (1997). O papel do Psicólogo. Estud. psicol. (Natal), 2(1). Recuperado em em 09 set. 2007, da SciELO (Scientific Electronic Library Online): http://www.scielo.br/ scielo.php?script $=$ sci_arttext\&pid $=\mathrm{S} 1413$ 294X1997000100002\&lng=pt\&nrm $=$ iso.

Triviños, A. N. S. (1987). Introdução à pesquisa em ciências sociais: A pesquisa qualitativa em educação. São Paulo: Atlas.

Vigotski, L. S. (2001). A construção do pensamento e da linguagem. São Paulo: Martins Fontes.
Recebido: 14/02/2008

Received: 02/14/2008

Aprovado: 03/03/2008 Approved: 03/03/2008 